a. wide and generous training in science would do more to provide such people than the narrow and intensively specialised courses favoured by some universities.

It is possible that the conference did not reach conclusions as explicit and as concrete as some might have wished. Nevertheless, the addresses and discussions were highly appreciated and were found stimulating and helpful. Wide agreement with the ideals of more generalised science teaching was shown, though it was evident that quite a number of teachers are not yet convinced of its benefits.

\title{
Food and the Family Budget
}

$\mathrm{T}$ HAT the social and economic aspects of national nutrition are evoking great public interest was shown by the crowded audience at the joint meeting of the Engineers' Study Group on Economics (E.S.G.) and the Association of Scientific Workers, held on March 31 at the house of the Royal Society of Arts, London. In a short introductory speech, Sir Richard Gregory urged the importance of investigating the causes why commodities that can now be produced in abundance, thanks to science, are not available in sufficient quantities to raise the standard of living of the people. He then called upon Dr. E. H. Tripp to present and explain the Group's report on "The Design of a Family Budget, with special reference to Food".*

The main finding of the report is that the statistical average family of 3.72 persons requires annually, for adequate living, goods and services now costing about $£ 317$, a sum equivalent to a weekly expenditure of about 63s. per wage-earner. About 82 per cent of 'families' are now earning less than this amount.

The chief items in the prescribed 'family' budget are (per annum) : food, £99; rent and rates, £55, the type of house envisaged being one containing a living-room, three bedrooms, kitchen and bathroom, costing $£ 600-£ 800$ inclusive of land; clothing, $£ 28$; fuel and light, divided between gas, electricity and but little raw coal, $£ 21$; smoking, liquor, and sweet-

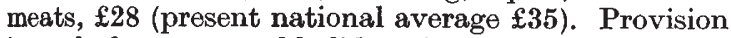
is made for an annual holiday, $£ 10$, and for travelling, $£ 20$ (present national average £22).

of especial importance in the prescribed dietary are the health foods, fresh dairy produce, eggs, meat, vegetables and fruit. The cost works out to $10 \mathrm{~s}$. a head per week, as compared with $9 s$, the current national average; and the conclusion is that a large section of the population has not the purchasing power needed to obtain the foods required for full health and working capacity.

In opening the discussion, Sir John Orr welcomed the fact that scientific workers have now begun to apply their knowledge and methods to social and economic problems, which cannot well be studied in water-tight compartments. The report of the E.S.G., he said, embodies an excellent study, and it is very remarkable that by approaching the subject from a totally different point of view and by different methods, the Group has reached a conclusion very close to that at which he and his colleagues arrived. Food requires a special place for itself. Whereas expenditure on items like entertainment, sport, and reading may vary from nothing to $£ 1,000$ a year, that on food varies much less from class to classnot more than from $4 s$. to 14s. a head per week between the poorest and the wealthiest. Appetite is limited, and although one might pay $£ 1$ for a dinner in London, one could not eat more than 10s. worth of food, at retail prices. Also, the State has assumed a special liability for food by undertaking to treat and cure diseases due to an inadequate diet. Very few people starve nowadays, but many lack a diet sufficient to maintain good health. To provide an adequate diet for all people below the income-level of $£ 317$ per annum would involve, at retail prices, an increase in the national expenditure of about 5-6 per cent ; but a cheaper method, and one more likely to be adopted, would be to cheapen the protective foodstuffs so that all could buy them; and that would reduce the increased expenditure to 1-2 per cent. More study and more criticism are needed to evoke concrete propositions; and once the bulk of the people is convinced, great improvement would follow.

Sir Daniel Hall said that if we increased the amount of home-grown food from the present figure of less than 40 por cent to more than 50 per cent of our total supplies, agricultural conditions would have to be revolutionised. We should certainly grow all the protective foodstuffs we can, and our land is specially suited to grow them. He disapproved the policy of subsidising wheat and sugar because they are needed in war-time; they are concentrated foods that are obtainable from our colonies, and occupy relatively little space in a ship's hold. As our farmers are now being assisted to the extent of more than $£ 40,000,000$ per annum, they could reasonably be expected to grow what is best for the country.

Mr. G. D. H. Cole agreed with the main points of the report, but regretted that the cost of education was not discussed. The food budget was certainly no more than is desirable, and it would probably be necessary to provide a larger total income. Urgently needed now are more data on expenditure at the $£ 6-£ 10$ a week income-level, and a new complete inquiry into working-class budgets.

Mr. A. E. Feavearyear commented on the cost of the improved housing prescribed in the E.S.G. budget. There are now some $10 \frac{1}{2}$ million houses in the United Kingdom, worth $£ 4,000-£ 5,000$ million at present prices. Assuming a house to last a hundred years, the annual cost of replacement would not amount to $£ 50,000,000$. He advocated a fairly rapid replacement of all houses below the E.S.G. standard -not less than 3 millions-but that would cost at least $£ 1,500,000,000$, or more than the entire net annual savings of the nation for five years.

Lady (Rhys) Williams described a study of infant and maternal mortality as affected by nutrition, carried out in the Rhondda Valley under the National Birth. day Trust Fund. Necessitous mothers were given vitamin-bearing foods and 1 pint of milk a day for at least three months, with the result that the maternal death-rate fell from 11.29 in 1934 to 3.9 in 1935 . 
Mr. G. P. Crowden referred to the work of the British Medical Association and said that further efforts are needed to strengthen the link between laboratory and kitchen. He suggested the establishment of a central bureau to give information on matters relating to family nutrition, and that pur. veyors of foodstuffs might assist purchasing and distribution by offering attractive terms to housewives for weekly supplies of items in the dietary scales recommended.
Dr. G. C. M'Gonigle thought the E.S.G. report a notable contribution to family economics. He has analysed many budgets of the lowly paid and unemployed, and has found that the relatively low standard of the B.M.A. minimum dietary cannot be achieved under a family income of 55-65s. a week. High rent is a great obstacle. Contrary to popular belief, he found that the average working-class woman has a sound empirical knowledge of practical dietetics, and to the limit of her purse buys wisely and well.

\section{Micro-Ray Communication}

$\mathrm{I}^{\mathrm{N}}$ engineering, the progress of the evolution of inventions seldom proceeds along a straight line, each step leading directly and logically to its successor. The evolution often proceeds in a looped path, new inventions apparently returning to an earlier stage of development before making a new start in another direction. This is illustrated in a paper read by W. L. McPherson and E. H. Ullrich to the Institution of Electrical Engineers on January 30.

In describing the recent commercialisation of micro-ray transmissions for radio communication, the authors point out that it was with micro-rays that Hertz in 1887 performed the classic experiments which are generally admitted to have led to the wireless communication of to-day. Hertz succeeded in generating by means of a spark transmitter wavelengths of $30 \mathrm{~cm}$., and in proving conclusively that the radiation due to such circuits followed the optical laws of reflection, refraction and propagation. He thus verified Clerk Maxwell's work done twenty-two years previously. Hertz's investigations read almost like an experimental and theoretical study of light. They include the measurements of the angles of incidence and reflection from plane sheets of metal, reflection from curved metallic mirrors of definite focal length, refraction through prisms of pitch and studies in transparency and opacity. Owing to lack of sensitivity on the receiving side, Hertz's experiments bore no immediate fruit although scientific workers were greatly interested in them.

The invention of the large aerial and of tuning, and the success of medium and long wave operation, led to practically total neglect of micro-ray technique until 1919, when Barkhausen and Kurz discovered a new type of oscillatory circuit which generated wave. lengths down to about $43 \mathrm{~cm}$. The first large-scale demonstration of modern micro-ray working was made between St. Margaret's Bay, near Dover, and Escalles, near Calais, a distance of $22 \cdot 1$ miles. The wave-length used was only $18 \mathrm{~cm}$. and so the waves radiated like light waves, permitting the use of reflecting mirrors. In January 1934 a micro-ray link for commercial service was opened between the aerodromes of Lympne in England and St. Inglevert in France, covering a distance of thirty-five miles. It provides a duplex service on radio-telephony, teleprinter or Morse telegraphy as required. The wavelength is $17.4 \mathrm{~cm}$., which is the shortest of any station in the world.

Experiments have shown that atmospherics of the ordinary type are never heard on the St. Margaret's circuit, although a few sharp clicks are sometimes noticed the origin of which has not yet been traced.
Thunderstorms occurring even in sight of the receiving station cause no interference. The ignition systems of aircraft or motor-boats also have no effect. It was found that the strength of the received signals did not remain constant. On three occasions the signal was uncommercial in telegraphy for periods of about two minutes. When a $600 \mathrm{~cm}$. wave-length was used, no variation of the received signal was ever detected.

Diagrams are given of the working signal current operating the teleprinter at Lympne and of the state of the tides at the same times. Although the effect of the tides may be masked in many instances by other fading causes, the records suggest that they are a factor in causing fading. In nine cases out of ten, the turn of the tide, during a week's record, was accompanied by a marked change in the slope of the signal current curve. This supports the hypothesis that there exists interference due to the indirect ray reflected at the sea surface.

The authors conclude that the primary condition for good micro-ray working is a thoroughly well-mixed and homogeneous atmosphere. In the summer, currents of hot air probably create 'pockets' of very different refractive power from the rest of the atmo. sphere, so that the direction of transmission may be violently changed and unusual attenuation intro. duced. In summer, the passage of a cloud across the sun's rays gives a temperature 'kick' the magnitude of which is different when above land than when above the sea, owing to the difference in reradiation in the two cases. The path of the St. Margaret'sEscalles link is at first sight simpler, as it is nearly all above the sea; but at the faces of the cliffs near the stations strong currents of hot air often arise, and this would introduce a compound lens effect in the path of the transmission rays.

The results obtained by the practical working of the two 'links' described in the paper may be sum. marised as follows. The most stable micro-ray conditions coincide with very stable atmospheric conditions, as judged by thermometer and barometer. A high wind is almost invariably accompanied with good micro-ray transmission. The settling of a heavy bank of fog has been accompanied by very severe and rapid changes in the reception, followed by stability when the fog bank has ceased to move. Radio waves, six metres in length, are much more stable than micro-waves over optical paths across the Straits of Dover. It is much more difficult to tap micro-wave communications than those which use longer wave-lengths. Hence when secrecy is necessary, as in military operations, they are more desirable. 